\title{
An Analysis of the Relationship between Quality Cues and Quality Attributes in the Purchase of Fresh Produce by Malaysian Consumers
}

\author{
N. Chamhuri and P.J. Batt \\ Curtin University \\ Australia
}

Keywords: fresh produce, quality cues, quality attributes, consumer intercept survey, Malaysia

\begin{abstract}
Consumers' preferences and the decision to purchase fresh produce from a retail store are based on a variety of quality cues. In the quality perception process, quality cues are associated with desired quality attributes (values). Malaysian consumers in the Klang Valley most often associate the appearance of the fresh produce (freshness, colour and firmness) with good taste. Fresh fruit and vegetables without any chemical residues, freedom from pests and diseases, and the origin of the produce were suggested as having a strong correlation with food safety and a beneficial impact on the environment and worker welfare. However, the quality cues utilised by consumers to associate fresh fruit and vegetables that taste good, that are safe, and produced in a way that is good for the environment and worker welfare varies significantly between each desired value.
\end{abstract}

\section{INTRODUCTION}

The basic function of food is to provide nutrition and energy for physical wellbeing, but food is also a major source of pleasure, worry and stress (Rozin et al., 1999). Wilcock et al. (2004) discussed that in order to reduce the uncertainty, most consumers make an implicit assumption that the food is safe to eat, aesthetically pleasing, good to taste and consistent with the product image. In 1996, the Food Marketing Institute reported that the majority of consumers were confident that the food they purchased was safe (Wilcock et al., 2004). According to Miles et al. (1999) most consumers believed that they were at less risk from food hazards. Furthermore, most consumers trusted the relevant government agencies and food processing companies that were responsible for ensuring food safety. Peri (2006) highlighted the importance of certification and traceability as instruments offered by food producers and manufacturers as a guarantee to consumers that the food was safe. However, several researchers have also shown that most consumers are unaware of the potential hazards food presents (Sockett, 1995; Woodburn and Raab, 1997; Worsfold and Griffith, 1997).

Perceived quality is a term that is frequently used to describe consumers' quality judgements. These are built on the consumers' perceptions, needs and objectives. Steenkamp (1990) focused on the theoretical concepts of the food quality perception process. Rokeach (1973) sought to develop a relationship between perceived quality and value. Value is seen as the core concept in social science. Value has been defined as a relativistic preference characterising a subject's interaction experience with some object (Holbrook and Corfman, 1983). 
Steenkamp (1990) defined perceived quality as an idiosyncratic value judgement with respect to the fitness for consumption, which was based upon the conscious and/or unconscious processing of quality cues in relation to relevant quality attributes, within the context of significant personal and situational variables. When consumers select a particular food, their preferences are based on several sensory characteristics (taste, texture and odour) and non-sensory attributes (health, price, religious, ethical concerns and mood) (Prescott et al., 2002).

Fieldhouse (1995) introduced the concept of food ideology, which is defined as a combination of attitudes, beliefs, customs and taboos affecting the diet of a given group. It was reported by Rozin (1996) [cited in Prescott et al., 2002] that culture provides the strongest determinant of food choice. Each consumer eats in their own way, depending on what values and beliefs they possess (Steenkamp, 1990). However, Fieldhouse (1995) agrees with Steenkamp (1990) that most consumers are unaware of the influence these ideologies exert upon their behaviour.

This paper focuses on how Malaysian consumers associate the criteria that they utilise in their decision to purchase fresh produce with food safety, taste, concern on the environment and worker welfare.

\section{THE MALAYSIAN FOOD INDUSTRY}

The Malaysian economy today is heavily reliant on manufactured goods. However, the former Prime Minister of Malaysia, Tun Abdullah Ahmad Badawi, recognised the importance of agriculture to the national economy, proclaiming it to be the "third engine of growth". Growth in the food industry is required to fulfil the needs of an increasing population. However, with strong economic growth, the need, preferences, lifestyle and the way Malaysian consumers consume their food is changing. Today, more Malaysians are eating more food away from home, there is a greater demand for more convenience and a greater range of food is available in retail stores.

According to the Malaysian Industrial Development Authority (MIDA), in 2008, Malaysia exported food products such as cocoa (RM 3 billion), fisheries products (RM 2.5 billion), margarine and shortening (RM 2.4 billion) and animal feed (RM 1.2 billion) to more than 200 countries. However, the Malaysian food industry is dominated by small and medium sized enterprises in such areas as fisheries, livestock, fresh fruit and vegetables and cocoa. Insufficient domestic food production has resulted in food imports becoming the major source of Malaysia's food supply (War et al., 2008). Among the major food imports are cereals, fisheries products, fruit and vegetables, sugar, honey and meat (The Ninth Malaysia Plan, 2006).

China is the leading vegetable exporter to Malaysia, followed by India, Thailand and Australia (War et al., 2008). From 1995 to 2006, Malaysian imports of vegetables from China increased from USD 80 million to USD 200 million.

The increasing import of food from China and other countries presents a potential risk to public health in Malaysia. For example, food imported from China often contains banned substances, antibiotics, preservatives and pesticides. Despite the warnings from Hong Kong and Singapore health authorities on the danger of food products produced in China, Malaysian authorities have thus far failed to conduct more stringent checks on the quality of imported food products.

\section{A MODEL OF PERCEIVED QUALITY}

Quality cues are defined as information stimuli that are related to the quality of the product and can be ascertained by the consumer through the senses prior to 
consumption (Steenkamp, 1990). Consumers are offered a large number of quality cues in the market. In the consumers' mind, desired cues are gathered and categorised, before making predictions of product quality. How the cues are gathered and categorised are based upon the beliefs and prior knowledge of the product that consumers have experienced. Quality cues include:

Implicit cues. These are derived from consumers' perception that the food they are about to consume is safe (Peri, 2006)(Figure 1).

Intrinsic cues. These are identified as the physical aspects of the product such as appearance, colour, shape, size and structure (Olson and Jacoby, 1972).

Extrinsic cues. These are not related to the physical product, but become an important indicator when comparing between two or more products that are similar in appearance. Examples include price, brand and country-of-origin labelling (Olson and Jacoby, 1972).

Credence cues. These denote features of the product which are considered important by the consumer, but are not experienced directly in consumption (Becker, 1999). These include nutrition, sustainability of agricultural production systems, genetically modified food, animal welfare, farm labour conditions and child labour (Steenkamp, 1990).

Quality attributes are defined as the functional and psychosocial benefits or consequences provided by the product (Steenkamp, 1990). This implies that quality attributes are the expected benefits that a consumer will experience after consumption. With regards to food, Peri (2006) introduced a total of five requirements for food quality, which included:

Safety requirements. This revolves around the absence of risk. It is further described as controlling biological, chemical and physical contamination (Batt et al., 2006). Food safety requirements for fresh produce are important compared to other types of agricultural products (Martinez and Poole, 2004). Since most fresh produce is perishable, the susceptibility to damage and disease is high. According to Shepherd (2006), the quality and safety of fresh produce affects the whole horticultural production and marketing chain; from the soil used to cultivate the crop, polluted water, if used for irrigation and washing harvested produce; untreated manure; and handling by retailers and consumers in store. Although the presence of microbial contamination brings serious threats to human health, consumers cannot readily detect the presence of dangerous substances such as viruses, bacteria and parasites on the fresh produce they purchase. Therefore, trusting the retail outlet or preferred vendors from whom they usually buy is one way of ensuring that the produce they purchase is safe to eat. However, as much of the fresh produce purchased is consumed raw or with minimal preparation, the problem can be accentuated. The extensive use of agrochemicals can also compromise food safety, for studies in Asia have repeatedly demonstrated that the usage of these agrochemicals is seldom in accordance with label recommendations (Shepherd, 2006).

Commodity requirements. These are defined as the conformity of the product according to the law. The demand for food safety globally has raised concerns about the impact of food regulators on international trade, particularly towards the developing countries (Martinez and Poole, 2004). Developing countries are foreseen as facing difficulties in meeting the higher levels of sanitary and phyto-sanitary regulation demanded by importing countries.

Nutritional requirements. This is one of the main purposes of eating. Consuming nutritious food provides health benefits and strengthens the body against diseases. Furthermore, consumers are increasingly turning towards products with low fat, low 
sugar, no preservatives and no artificial colours or flavour enhancers (Lappalainen et al., 1998; Prescott et al., 2002). Food safety and nutritional requirements are most often associated with the credence cues (something implicit) which are based upon a consumer's experience.

Sensory requirements. According to Peri (2006), sensory requirements connect food and consumers. Becker (1999) categorised the sensory attributes as taste and juiciness. Taste is based on the observation of the food, and is influenced by the environment, geography, demography, socio-demography and psychological variables (Sijtsema et al., 2002). For example, women perceive taste, flavour and texture as being more important than men (Ragaert et al., 2004).

Production and ethical requirements. Consumers are concerned about how, when and where their food is produced. In Asia, for example, county-of-origin is currently perceived to be the most important piece of information consumers require in their decision to purchase a particular food product (Batt et al., 2006). Furthermore, consumers are showing a greater interest in the ethical values of food production, which includes organic agriculture, concern for the environment, animal welfare and worker welfare (Becker, 1999; Peri, 2006). Findings by Prescott et al. (2002) demonstrate that Malaysian consumers are placing more emphasis on health, natural content (no additives, natural and no artificial ingredients), weight control and convenience, rather than any ethical concerns in their food choice behaviour.

For the purpose of this paper, the association between quality cues and quality attributes (desired values) shall be discussed with regards to food safety, sensory evaluation (taste) and the production and ethical requirements (environmental sustainability and worker welfare).

\section{METHODOLOGY}

Random shopping mall intercepts were used for data collection. Over many years, the shopping mall intercept method has emerged as one of the most popular methods among marketing researchers (Bush and Hair, 1985; Hornik and Ellis, 1989). The study was conducted in several modern retail outlets and traditional markets around the Klang Valley region. The areas chosen were based on the desire to capture a good mixture of income and education levels which could affect consumers' attitudes towards the purchase and consumption of fresh fruit and vegetables. In all, the sample consisted of 284 useable surveys (Table 1).

The survey instrument for this research contained a combination of both structured and open-ended questions. The questionnaire was divided into four sections. Section I sought to gather information regarding the store choice behaviour of the respondents and the quality of fresh fruit and vegetables. Section II sought to examine the respondents' behaviour towards the purchase of fresh potatoes, spinach and apples. Section III discussed how respondents react to dissatisfaction, while Section IV measured socio-demographic factors. This paper will report on the results from Section II.

The original survey was prepared in English. However, in order to improve the response rates, a Malay version of the survey was also prepared as not all of the population are expert in English.

\section{RESULTS AND DISCUSSION The Food is Safe to Eat}

In identifying that the fresh produce was considered safe to eat, for all three products (potatoes, spinach and apples), freedom from chemical residues, pests and 
diseases, and organic were most frequently cited by respondents (Table 2). Freshness was also frequently cited by respondents as being associated with food that was safe to eat. In determining whether spinach or apples were safe to eat, respondents also cited freedom from blemishes and bruises. For potatoes and spinach, freedom from soil was an indication that the food was safe to eat. Given that most of the potatoes and apples sold in Malaysia are imported, respondents demonstrated their concerns with regard to the origin of the potatoes and apples available in a retail store. However, respondents showed little interest with regards to the origin of spinach, since most spinach was locally grown.

Label or brand, was among the most infrequently cited variables which were considered indicative of food safety for all three fresh products. Two other variables that were infrequently cited by respondents in determining whether the potatoes and apples were safe to eat were the availability of product information in-store and the place of purchase.

\section{The Food has a Good Taste}

Most respondents indicated that the appearance of the produce (freshness, colour and firmness) were important indicators of good taste (Table 3).

Spinach and apples without blemishes and bruises were considered indicative of good taste. For potatoes, good flesh colour was another variable often cited by respondents as indicative of good taste. Where the potatoes and apples were grown were also considered by respondents to have an impact on taste.

Again, in determining good taste, label or brand was one of the least cited variables by respondents in their decision to purchase fresh potatoes and apples.

\section{The Food has been Produced in a Way that is Good for the Environment}

Most respondents cited organic, freedom from chemical residues, and freedom from pests and diseases among the variables which were most associated with the production of all three crops in a manner that was conducive for the environment (Table 4).

The origin of the crop, whether it was imported or locally grown, and freshness were also indicative of production systems that were perceived to minimise the impact on the environment. Freedom from soil was another variable cited by respondents as having a positive impact on the environment for fresh potatoes and spinach.

The appearance, which included colour and size, promotional variables such as advertising in newspapers or catalogues, and pre-packaged produce were the variables cited less often by respondents as having any positive impact on the environment.

\section{The Food is has been Produced in a Way that Protects Worker Welfare}

Freedom from chemical residues and other variables which described how and where the fresh produce were grown, such as organically and locally grown were among the most frequently cited variables which respondents believed were associated with food production methods that protected workers welfare (Table 5).

Freedom from pests and diseases, and prepacked produce were also considered by respondents to be associated with produce that had been grown in such a way as to protect worker welfare. The country-of-origin and availability of product information at the point of purchase were cited for the purchase of fresh potatoes and apples and this was thought to have some impact on worker welfare. 


\section{CONCLUSIONS}

Similar to the findings by Abbott (1999) and Kader (2002), this research revealed that consumers evaluate good taste (sensory requirements) by evaluating the physical attributes (freshness, colour and firmness) of the fresh produce. Defective product including blemishes, bruises or sprouts were least often associated with good taste.

Clearly, respondents demonstrated the relationship between credence cues (organic and the origin of the produce), freedom from chemical residues and freedom from pests and diseases in ascertaining that the food was safe to eat and met prescribed production and ethical requirements. However, in the absence of any third party endorsements, any association between the cues and attributes could create a dilemma for the consumer in verifying that the fresh produce is safe to eat and was produced in a manner that protected the environment and worker welfare. Certification and traceability procedures such as Good Agricultural Practice (GAP) and Hazard Analysis Critical Control Point (HACCP) are required to offer consumer guarantees. In Malaysia, HACCP is still voluntary and not mandatory. Furthermore, findings by Toh and Birchenough (2000) reveal that food vendors in Malaysia were being urged to improve their knowledge and attitudes towards food safety and hygiene, foodborne illness and its prevention.

Results indicate that there is a demand for better quality and safe fresh products. However, it is unclear whether the traditional markets are able to supply better quality produce to consumers. Chamhuri and Batt (2009) reveal how Malaysian consumers continue to purchase fresh produce from preferred vendors in traditional markets. An element of trust is developed from personal relationships between vendors and consumers which signifies the quality and provides an assurance of safety for the fresh produce available from the traditional markets.

In Malaysia, there is little research available to identify the quality cues consumers utilise in determining that the food is safe, tastes good and was produced in a way that protects the environment and worker welfare. Therefore, this research intends to narrow the quality perception gap that exists between the producers, policy makers and consumers to improve the performance of the Malaysian fresh produce industry. For producers, the findings of this research may be useful in new product development, in terms of improving quality and differentiating food products from competitors. For the food quality authorities, the findings may assist in establishing standards in terms of food quality and food safety education in Malaysia.

\section{Literature Cited}

Batt, P.J., Noonan J. and Kenyon, P. 2006. Global trends analysis of food safety and quality systems for the Australian food industry. A report submitted to Department of Agriculture, Fisheries and Forestry, Canberra.

Becker, T. 1999. The economics of food quality standards presented at Second Interdisciplinary Workshop on Standardisation Research, University of the Federal Armed Forces Hamburg.

Bush, A.J., and Hair, J.F. 1985. An assessment of the mall intercept as a data collection method. J. of Marketing Research 32(November):385-391.

Chamhuri, N. and Batt, P.J. 2009. Consumer choice of retail outlet: Focus group interviews in Malaysia. Acta Hort. (ISHS) 831: 237-246.

Fieldhouse, P. 1995. Food and Nutrition, Customs and Culture. Chapman \& Hall, London. 
Holbrook, M. B. and Corfman, K.P. 1983. Quality and other types of value in the consumption experience: Phaedrus Rides Again. Working paper, Columbia University, New York.

Hornik, J. and Ellis, S. 1989. Strategies to secure compliance for a mall intercept interview. Public Opinion Quarterly 52(4):539-551.

Kader, A.A. 2002. Quality parameters of fresh-cut fruit and vegetables products. p. 11-20. In: O. Lamikanra (ed), Fresh-cut fruits and vegetables, Science, Technology and Market, CRC Press: Boca Raton, FL.

Lappalainen, R., Kearney, J. and Gibney, M. 1998. A pan EU survey of consumer attitudes to food, nutrition and health: An overview. Food Quality and Preference 9: 467-478.

Malaysian Industrial Development Authority. 2009. www.mida.gov.my accessed $27^{\text {th }}$ October 2009.

Martinez, M.G. and Poole, N. 2004. The development of private fresh produce safety standards: implications for developing Mediterranean exporting countries. Food Policy 29:229-255.

Miles, S., Braxton, D.S. and Frewer, L.J. 1999. Public perceptions about microbiological hazards in food. British Food Journal 101:744-762.

Olson, J.C. and Jacoby, J. 1972. Cue utilization in the quality perception process in Venkatesan, M. (ed) Proceedings of The Third Annual Conference of the Association of Consumer Research, Association for Consumer Research, Iowa City, 67-79.

Peri, C. 2006. The universe of food quality. Food Quality and Preference 17:3-8.

Prescott, J., Young, O., O’Neill, L., Yau, N.J.N. and Stevens, R. 2002. Motives for food choice: a comparison of consumers from Japan, Taiwan, Malaysia and New Zeland. Food Quality and Preference 13:489-495.

Ragaert, P., Verbeke, W., Devlieghere, F. and Debevere, J. 2004. Consumer perception and choice of miniminally processed vegetables and packaged fruits. Food Quality and Preferences 15:259-270.

Rokeach, M.J. 1973. The Nature of Human Values, The Free Press, New York.

Rozin, P. 1996. The socio-cultural context of eating and food choice. In: Meiselman, H. and MacFie, H.J.H. (eds.), Food choice, acceptance and consumption. London: Blackie: 83-104.

Rozin, P., Fischler, C., Imada, S., Sarubin, A. and Wrzesniewski, A. 1999. Attitudes to food and the role of food in life in the USA, Japan, Flemish Belgium and France: possible implications for the diet-health debate. Appetite 33:163-180.

Shepherd, A.W. 2006. Quality and safety in the traditional horticultural marketing chains of Asia. AGSF Occasional Paper 13, FAO, Rome.

Sijtsema, S., Linnemann, A., Van Gaasbeek, T., Dagevos, H. and Jongen, W. 2002. Variables influencing food perception reviewed for consumer-oriented product development. Critical Reviews in Food Science and Nutrition 42(6):565-581.

Sockett, P.N. 1995. The epidemiology and costs of diseases of public health significance in relation to meat and meat products. J. of Food Safety 15:91-112.

Steenkamp, J-B.E.M. 1990. Conceptual model of the quality perception process. J. of Business Research 21:309-333.

Toh, P.S. and Birchenough, A. 2000. Food safety knowledge and attitudes: culture and environment impact on hawkers in Malaysia. Knowledge and attributes are key attributes of concern in hawker foodhandling practices and outbreaks of food poisoning and their prevention. Food Control 11:447-452. 
Warr, S., Rodriguez, G. and Penm, J. 2008. Changing food consumptions and imports in Malaysia: Opportunities for Australian agricultural exports, ABARE research report 08.6 for the Australian Government Department of Agriculture, Fisheries and Forestry, Canberra, August.

Wilcock, A., Pun, M., Khanona, J. and Aung, M. 2004. Consumer attitudes, knowledge and behaviour: A review of food safety issues. Trends in Food Science and Technology 15(2): 56-66.

Woodburn, M.J. and Raab, C.A. 1997. Household food preparers' food-safety knowledge and practices following widely publicized outbreaks of foodborne illness. J. of Food Protection 60(9):1105-1109.

Worsfold, D. and Griffith, C. 1997. Food safety behaviour in the home. British Food Journal 99(3):97-104.

Figure 1: A model of perceived quality

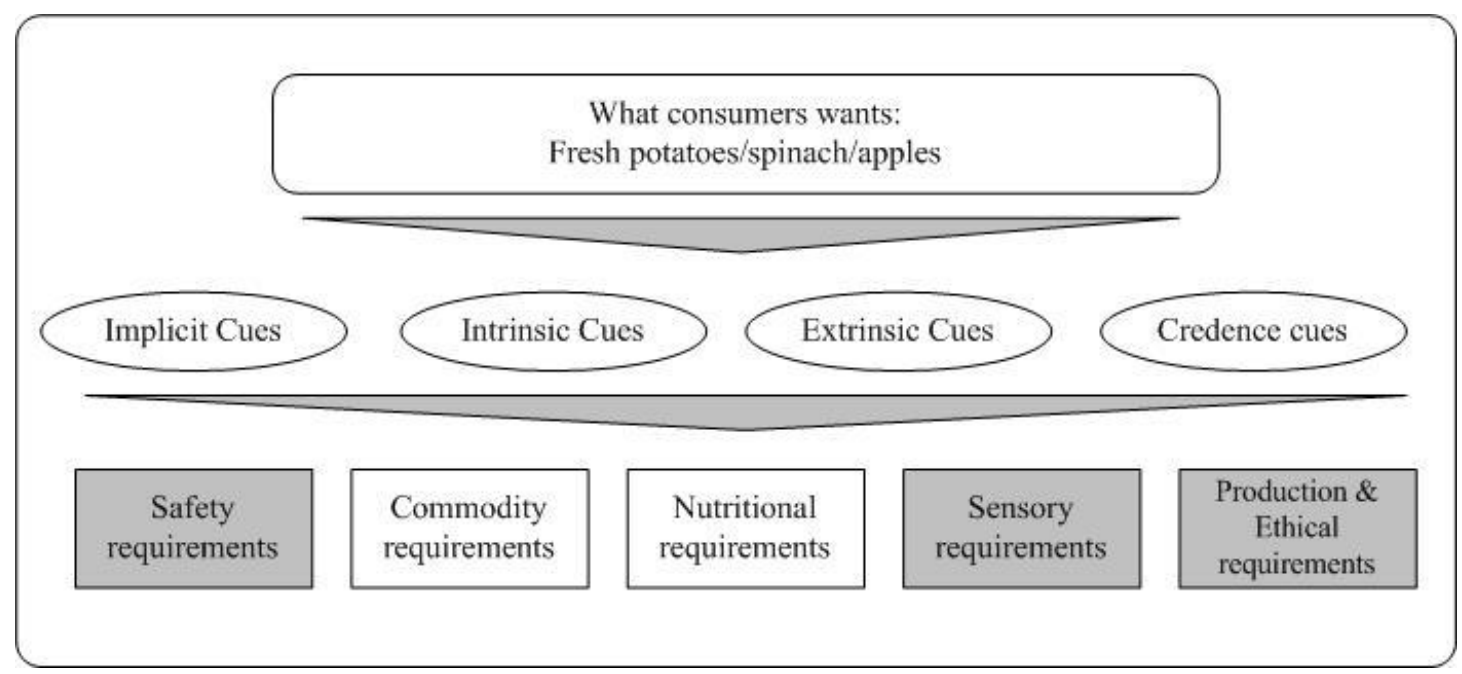

Source: Adapted from Steenkamp (1990) and Peri (2006)

Table 2: The correlation between criteria utilised in the decision to purchase fresh produce with the food safety

\begin{tabular}{|l|c|c|c|c|}
\hline The fresh produce is safe to eat & Potatoes & Spinach & Apple & N \\
\hline Freedom from chemical residues & 144 & 112 & 140 & 396 \\
\hline Freedom from pests and diseases & 113 & 88 & 93 & 294 \\
\hline Organic & 28 & 56 & 43 & 219 \\
\hline Freshness & 29 & 24 & 39 & 92 \\
\hline Freedom from blemish and bruise & & 31 & 47 & 78 \\
\hline Free from soil & 34 & 30 & & 64 \\
\hline Skin colour/colour & 18 & 18 & 11 & 47 \\
\hline Origin of the fruit & 12 & & 19 & 31 \\
\hline Washed & 29 & & & 29 \\
\hline Freedom from sprouting & 19 & & & 19 \\
\hline Flesh colour & 15 & & & 15 \\
\hline Locally grown & 3 & 10 & & 13 \\
\hline Free of wilting & & 13 & & 13 \\
\hline Firmness & 4 & & 8 & 12 \\
\hline Label or brand & 4 & 1 & 3 & 8 \\
\hline Availability of product information in-store & 3 & & 2 & 5 \\
\hline Place of purchase & 1 & & 1 & 2 \\
\hline
\end{tabular}


Table 1: Profile of respondents

\begin{tabular}{|l|l|c|c|}
\hline Characteristics & Category & Frequency & Percentage \\
\hline Gender & Male & 58 & 20.4 \\
\cline { 2 - 4 } & Female & 226 & 79.6 \\
\hline \multirow{5}{*}{ Age } & $18-25$ years old & 40 & 14.1 \\
\cline { 2 - 4 } & $26-34$ years old & 144 & 50.7 \\
\cline { 2 - 4 } & $35-44$ years old & 51 & 18.0 \\
\cline { 2 - 4 } & 45-54 years old & 37 & 13.0 \\
\cline { 2 - 4 } & 55-64 years old & 12 & 4.2 \\
\cline { 2 - 4 } & 65 and above & 0 & 0.0 \\
\hline Education level & Primary school & 3 & 1.1 \\
\cline { 2 - 4 } & Secondary school & 70 & 24.6 \\
\cline { 2 - 4 } & Diploma & 70 & 24.6 \\
\cline { 2 - 4 } & First degree/professional certificate & 84 & 29.6 \\
\cline { 2 - 4 } & Postgraduate & 57 & 20.1 \\
\hline Ethnicity & Malay & 256 & 90.1 \\
\cline { 2 - 4 } & Chinese & 12 & 4.2 \\
\cline { 2 - 4 } & Indian & 6 & 2.1 \\
\cline { 2 - 4 } & Others & 10 & 3.5 \\
\hline Monthly income & Less than RM1,500 & 25 & 8.8 \\
\cline { 2 - 4 } & RM1,501 - RM3,000 & 75 & 26.4 \\
\cline { 2 - 4 } & RM3,001 - RM4,500 & 25 & 24.6 \\
\cline { 2 - 4 } & RM4,501 - RM6,000 & 23 & 8.3 \\
\cline { 2 - 4 } & RM6,001 - RM7,500 & 17 & 8.1 \\
\cline { 2 - 4 } & RM7,501 - RM9,000 & & 6.0 \\
\cline { 2 - 4 } & RM9,001 and above & \\
\hline
\end{tabular}

Table 3: The correlation between criteria utilised in the decision to purchase fresh produce with good taste

\begin{tabular}{|l|c|c|c|c|}
\hline The fresh produce has a good taste & Potatoes & Spinach & Apple & N \\
\hline Freshness & 131 & 106 & 152 & 389 \\
\hline Skin colour/colour & 55 & 73 & 91 & 219 \\
\hline Firmness/Firmness of the stem & 81 & 34 & 62 & 177 \\
\hline Freedom from blemish and bruise & & 26 & 51 & 77 \\
\hline Flesh colour & 66 & & & 66 \\
\hline Leaves & & 65 & & 65 \\
\hline Country-of-origin & 21 & & 34 & 55 \\
\hline Freedom from chemical residues & 17 & 15 & 15 & 47 \\
\hline Free from wilting & & 38 & & 38 \\
\hline Organic & 11 & 19 & 8 & 38 \\
\hline Freedom from pests and diseases & 17 & 6 & 10 & 33 \\
\hline Variety & 12 & 6 & 9 & 27 \\
\hline Freedom from sprouting & 18 & & & 18 \\
\hline Washed & 15 & & & 15 \\
\hline Label or brand & 1 & & 9 & 10 \\
\hline Free from soil & 6 & 3 & & 9 \\
\hline
\end{tabular}


Table 4: The correlation between criteria utilised in the decision to purchase fresh produce with food production that is good for the environment

\begin{tabular}{|l|c|c|c|c|}
\hline $\begin{array}{l}\text { The fresh produce has been produced in a } \\
\text { way that is good for the environment }\end{array}$ & Potatoes & Spinach & Apple & N \\
\hline Organic & 141 & 117 & 117 & 375 \\
\hline Freedom from chemical residues & 93 & 96 & 108 & 297 \\
\hline Freedom from pests and diseases & 45 & 49 & 40 & 134 \\
\hline Locally grown & 39 & 25 & & 64 \\
\hline Freshness & 14 & 11 & 15 & 40 \\
\hline Country-of-origin & 7 & & 27 & 34 \\
\hline Free from soil & 10 & 18 & & 28 \\
\hline Label or brand & 8 & & 10 & 18 \\
\hline Firmness of the fruit/stem & 5 & 3 & 5 & 13 \\
\hline Availability of product information in-store & 5 & & 7 & 12 \\
\hline Freedom from blemish and bruise & & 4 & 8 & 12 \\
\hline Skin colour/colour & 2 & 2 & 5 & 9 \\
\hline Newspaper advertising/catalogues & 5 & & 3 & 8 \\
\hline Size & 4 & 1 & 3 & 8 \\
\hline Fruit/vegetable is prepacked & 2 & & 5 & 7 \\
\hline
\end{tabular}

Table 5: The correlation between criteria utilised in the decision to purchase fresh produce with food production that protects worker welfare

\begin{tabular}{|l|c|c|c|c|}
\hline $\begin{array}{l}\text { The fresh produce has been produced in a } \\
\text { way that protects worker welfare }\end{array}$ & Potatoes & Spinach & Apple & N \\
\hline Freedom from chemical residues & 82 & 84 & 78 & 244 \\
\hline Organic & 54 & 53 & 59 & 166 \\
\hline Locally grown & 53 & 47 & & 100 \\
\hline Freedom from pests and diseases & 27 & 29 & 24 & 80 \\
\hline Country-of-origin & 18 & & 36 & 54 \\
\hline Fruit/vegetable is prepacked & 7 & 15 & 15 & 37 \\
\hline Availability of product information in-store & 14 & & 17 & 31 \\
\hline Competitive price & 10 & & 19 & 29 \\
\hline Newspaper advertising/catalogues & 10 & & 12 & 22 \\
\hline Label or brand & 8 & & 10 & 18 \\
\hline Freshness & 2 & 7 & 9 & 18 \\
\hline Advice from sales assistants & 14 & & & 14 \\
\hline Place of purchase & 11 & & 1 & 12 \\
\hline
\end{tabular}

